\title{
The Influence of Grain Size on Twinning and Microstructure Refinement During Cold Rolling of Commercial-Purity Titanium
}

\author{
S.V. ZHEREBTSOV, G.S. DYAKONOV, G.A. SALISHCHEV, A.A. SALEM, \\ and S.L. SEMIATIN
}

Microstructure evolution in commercial-purity titanium (CP Ti) with various initial grain sizes $(1,7,15$, and $30 \mu \mathrm{m})$ during plane-strain multipass rolling to a true thickness strain of 2.66 at $293 \mathrm{~K}\left(20^{\circ} \mathrm{C}\right)$ was established. The degree of deformation twinning was found to be strongly dependent on grain size. Twinning was rare in the material with a grain size of $1 \mu \mathrm{m}$. For all grain sizes $>15 \mu \mathrm{m}$, the occurrence of twinning reached a similar, maximum level. Concurrently, the propensity for twinning enhanced the kinetics of microstructure refinement particularly for the initially coarse-grain materials. Due to the extensive twinning-induced microstructure refinement, rolling of coarse-grain $(15 \mu \mathrm{m}) \mathrm{CP}$ Ti to a true thickness strain of 2.66 resulted in the formation of an ultrafine microstructure with a grain/subgrain size of $200-300 \mathrm{~nm}$, a value similar to that attained for the initially micrometer-scale microstructure. The effect of grain size on twinning in titanium was discussed in the context of a disclination model.

DOI: $10.1007 / \mathrm{s} 11661-016-3679-0$

(C) The Minerals, Metals \& Materials Society and ASM International 2016

\section{INTRODUCTION}

THE initial grain size in metallic materials can have a considerable effect on microstructure evolution/refinement during large plastic strain. A coarse initial microstructure usually results in marked flow localization and heterogeneity of the final structure. By contrast, grain refinement to a micrometer scale improves the uniformity of deformation and facilitates the formation of homogeneous microstructures. ${ }^{[1]}$ In addition, smaller-grained microstructures often give rise to more rapid kinetics of deformation-induced microstructure refinement. ${ }^{[2,3]}$ For example, the rate of increase of the density of high-angle grain boundaries (and hence rate of microstructure refinement) during deformation of stainless steel was noticeably higher for an initial condition comprising a smaller grain size in comparison with its coarse-grain counterpart. ${ }^{[2]}$

S.V. ZHEREBTSOV, Head of Department, is with the Department of Materials Science and Nanotechnology, Belgorod State University, 85 Pobeda str, Belgorod, 308015, Russia. Contact e-mails: ser_z@mail.ru, zherebtsov@bsu.edu.ru G.S. DYAKONOV, Researcher, is with the Institute of Physics of Advanced Materials, Ufa State Aviation Technical University, K. Marks 12, Ufa 450000, Russia. G.A. SALISHCHEV, Head of Laboratory, is with the Laboratory of Bulk Nanostructured Materials, Belgorod State University. A.A. SALEM, President and CEO, is with Materials Resources LLC, Dayton, $\mathrm{OH}$ 45402. S.L. SEMIATIN, Senior Scientist, Materials Processing/Processing Science, is with the Air Force Research Laboratory, Materials and Manufacturing Directorate, AFRL/RXCM, Wright-Patterson Air Force Base, OH 45433.

S.L. Semiatin is employed by the Air Force Research Laboratory. U.S. Government work is not protected by U.S. Copyright.

Manuscript submitted December 17, 2015.
The effect of grain size on microstructure evolution can also be pronounced for polycrystalline hexagonal closepacked metals such as commercial-purity titanium (CP Ti). For these materials with a low-symmetry crystal lattice, there are two main mechanisms of deformation, slip and twinning, each of whose extent depends on grain size. This phenomenon is associated with the different dependences of critical resolved shear stress for slip and twinning on grain size ${ }^{[4-7]}$ The contribution of twinning decreases with a decrease in grain size. At a certain grain size, twinning is not observed. At room temperature, for instance, this critical grain size has been found to be $0.9 \mu \mathrm{m}$ for $\mathrm{CP} \mathrm{Ti}{ }^{[8]}$ and $1 \mu \mathrm{m}$ for $\mathrm{Ti}^{\mathrm{i}}-5 \mathrm{Al}{ }^{[9]}$ Because deformation twinning results in microstructure refinement, ${ }^{[8]}$ it can be surmised that the accommodation of large imposed strains by twinning $v$ slip could affect the nature and kinetics of the formation of ultrafine microstructures. However, there is relatively little quantitative data in the literature in this area. The aim of the present work, therefore, was to quantify the evolution of microstructure in $\mathrm{CP}$ Ti with various initial grain sizes (between 1 and $30 \mu \mathrm{m}$ ) subjected to multipass, planestrain rolling at $293 \mathrm{~K}\left(20^{\circ} \mathrm{C}\right)$ to an overall true thickness strain of 2.66. For this purpose, particular attention was focused on the development of deformation twinning at the initial stages of deformation and influence of twinning on the kinetics of microstructure evolution during large plastic strain.

\section{MATERIAL AND EXPERIMENTAL PROCEDURES}

The program material consisted of $\mathrm{CP} \mathrm{Ti}$ with impurity levels (in wt pct) less than $0.2 \mathrm{Fe}, 0.1 \mathrm{Si}, 0.07$ 
$\mathrm{C}, 0.04 \mathrm{~N}, 0.01 \mathrm{H}$, and $0.12 \mathrm{O}$. It was received in the form of a 30-mm-diameter, hot-rolled bar.

Microstructures with average grain sizes of $1,7,15$, and $30 \mu \mathrm{m}$ were obtained by annealing ultrafine-grain preforms at $753 \mathrm{~K}, 873 \mathrm{~K}, 973 \mathrm{~K}$, and $1023 \mathrm{~K}\left(480{ }^{\circ} \mathrm{C}\right.$, $600{ }^{\circ} \mathrm{C}, 700{ }^{\circ} \mathrm{C}$, and $800{ }^{\circ} \mathrm{C}$ ), respectively, ${ }^{[10]}$ extracted from material originally produced by isothermal multiaxial forging and bar drawing. ${ }^{[1]}$ The grain size distributions for specimens of $\mathrm{CP}$ Ti with average grain sizes of 7,15 , and $30 \mu \mathrm{m}$ (Figure 1) were quite narrow (standard deviations were $1.75,5.47$, and $9.25 \mu \mathrm{m}$, respectively) with some asymmetry toward small sizes due to the presence of grains much smaller than the nominal size. The grain size distribution for specimens with an average grain size of $1 \mu \mathrm{m}$ was noticeably broader (the standard deviation was $0.35 \mu \mathrm{m}$ ) and contained grains as large as $2.5 \mu \mathrm{m}$ (Figure 1). It should be noted that all of the observations in the present work were done on $2 \mathrm{D}$ sections. According to a theoretical solution based on well-established probability laws derived by $\mathrm{M}$. Kong with coauthors, ${ }^{[12]}$ the $2 \mathrm{D}$ average grain sizes can be converted to $3 \mathrm{D}$ by multiplying by a factor of 1.273 , irrespective of the particular distribution of the 3D size.

Prismatic (sheet-bar) samples for flat rolling, each measuring $30 \times 20 \times 4 \mathrm{~mm}$, were cut from the annealed materials with the rolling direction (RD) parallel to the prior drawing direction. Each sample was rolled at room temperature in a six-high mill using a fixed rolling speed of $30 \mathrm{~mm} / \mathrm{s}$. Unidirectional, multipass rolling to a total thickness strain between $\sim 0.05$ and $\sim 2.66$ was performed using a reduction per pass (i.e., draft) of approximately $0.2-0.07 \mathrm{~mm}$.

The microstructure and crystallographic orientation at the mid-thickness rolling plane of each sample were determined using light microscopy, transmission electron microscopy (TEM), and electron backscatter diffraction (EBSD). EBSD was conducted in a Quanta 600 field emission gun scanning electron microscope (FEG SEM) equipped with a TSL OIM ${ }^{\mathrm{TM}}$ system (Version 5.2). The fractions of high-confidence-index points were $\sim 98$ and 80 pet for the initial and strained conditions, respectively. To improve the reliabllity of the

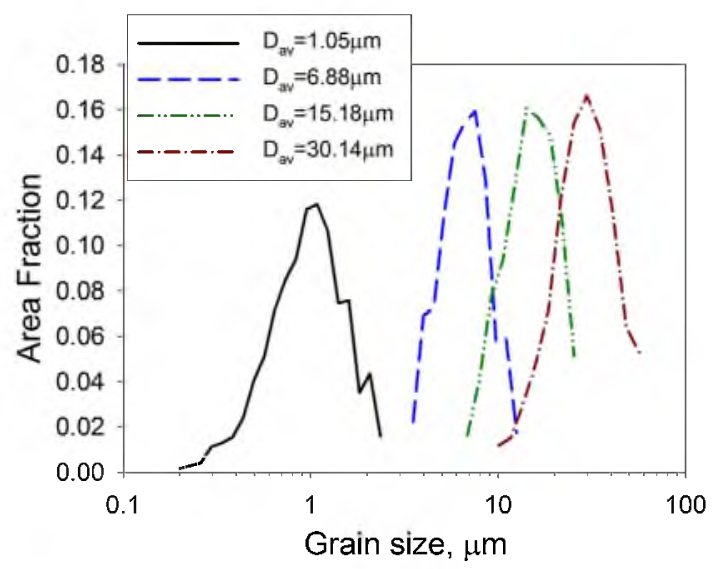

Fig. 1-Grain size distributions in $\mathrm{CP}$ Ti samples obtamed by annealing ultrafine-gram preforms at different temperatures.
EBSD data, grains comprising three or fewer pixels were automatically removed from the maps using the grain-dilation option in the TSL software. The density of boundaries was calculated as the ratio of the total length of boundaries (either low-angle or high-angle) to the area of the scan. A 15-deg criterion was used to differentiate low-angle boundaries (LABs) and high-angle boundaries (HABs). In the EBSD maps, LABs were depicted as gray, and HABs were black. The fraction of twinned grains was determined as the ratio of grains which contained at least one twin to the total number of grains. Twins of different systems were determined in the TSL software using known angle-axis pairs ${ }^{[6]}$ adjusted for the Brandon criteria. ${ }^{[13]}$ The activity of various twin systems during deformation was assumed to be proportional to the fraction of the corresponding twin boundary length relative to that of all of the high-angle grain boundaries.

TEM was done in a $200 \mathrm{kV}$ JEOL JEM-2100FX. Matrix/twin misorientation angles were quantified by indexing microdiffraction patterns and determination of the misorientation matrix along the routine procedure.

To obtain statistically meaningful data, ${ }^{[14]}$ the population of grains and twins examined in the EBSD analysis exceeded few hundreds (and in some cases attained one-two thousands) for each strain/grain size. TEM analysis was also made for each grain size and strain level; however, the number of studied grains was smaller and usually fell into the interval 50-100 grains depending on the initial grain size. For specimens with an average grain size of $1 \mu \mathrm{m}$, the quantitative TEM analysis (fraction of grains twinned and width of twins, Figure 11) was made using 3-5 foils for each strain; the number of grains examined was 40-60 in each foil with the total amount of grains larger than 150 .

\section{RESULTS}

\section{A. Microstructure and Texture Evolution}

The initial textures of specimens with the different grain sizes obtained from the EBSD data were similar (but not identical) (Figure 2). In broad terms, the textures comprised primarily a split-basal component rotated from the normal direction (ND) toward the transverse direction (TD) by $-30-90 \mathrm{deg}$. For the material with a $1-\mu \mathrm{m}$ average grain size, the basal poles were near the ND, whereas they were rotated to a greater extent away from the ND toward the TD for the samples that were coarse grained (especially those with $15-$ and $30-\mu \mathrm{m}$ grain sizes).

In the initial condition, the microstructure of $\mathrm{CP} \mathrm{Ti}$ specimens with the finest grain size consisted of equiaxed grains with $d \approx 1 \mu \mathrm{m}$. There were no twins in the microstructure (Figure 3(a)). However, some grains contained subboundaries. Microstructure evolution during rolling consisted of grain elongation along the RD and a considerable increase in the fraction of LABs. At low levels of reduction, LABs formed preferably nearby the initial grain boundaries. Deformation twins were not observed at any stage of rolling, however (Figure 3(b)). 


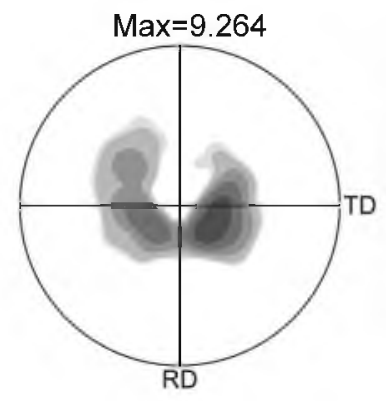

(a)

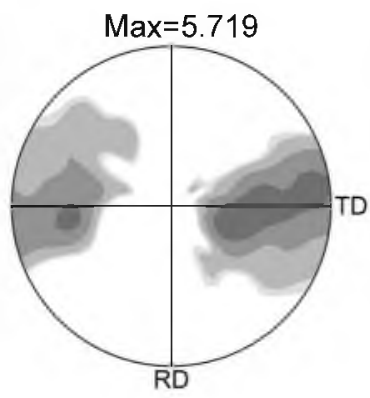

(b)

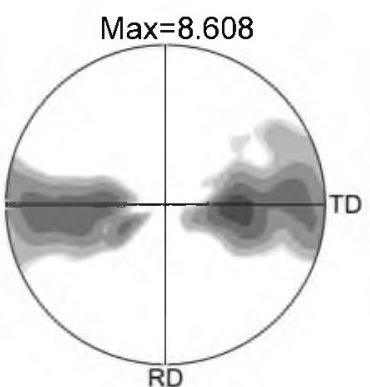

(c)

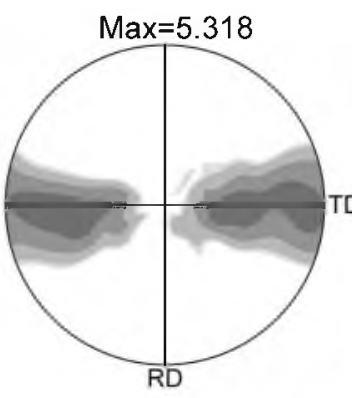

(d)

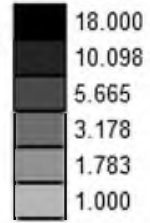

(e)

Fig. 2-EBSD (0001) pole figures taken from the rolling plane of CP Ti samples with average initial graim sizes of (a) 1, $(b) 7$, (c) 15, and (d) $30 \mu \mathrm{m}$. The times random scale in (e) applies to all of the pole figures here and in the remamder of the paper.

Nevertheless, the structure was refined with strain. After a thickness strain of 2.66, a heterogeneous microstructure with a grain/subgrain size of $0.3 \mu \mathrm{m}$ was formed (Figure 3(c)). However, rather large remnant of grains and subgrains were also observed.

Texture evolution during cold rolling of $\mathrm{CP} \mathrm{Ti}$ specimens with $d \approx 1 \mu \mathrm{m}$ was associated with the transformation of the initial split-basal texture (Figure 2(a)) to a more-pronounced basal-normal texture (inserts in Figures 3(a)-(c)). This behavior has been observed before for cold rolling of $\mathrm{CP}$ Ti deforming by slip. ${ }^{[15]}$

For samples with a starting grain size of $7 \mu \mathrm{m}$, some twins were observed in the initial condition. The number of twins increased noticeably by a reduction of 30 pct (Figure 4(a)). Much like the sample with the 1- $\mu \mathrm{m}$ initial grain size, the grains became elongated along the RD, and LABs formed within the majority of grains. After 60 -pct thickness reduction, the microstructure contained (sub)grains of various sizes and forms (Figure 4(b)). Some boundaries (or, more often, parts of boundaries) exhibited a nearly ideal twin/matrix misorientation, which in conjunction with the elongated shape of the corresponding grains implied the presence of twin remnants within the microstructure. The microstructure after 93-pct thickness reduction comprised very large elongated and small-equiaxed grains/subgrains (Figure 4(c)). The average (sub)grain size was $0.6 \mu \mathrm{m}$.

During the early stage of deformation of samples with an initial grain size of $7 \mu \mathrm{m}$, the intensity of basal poles near the normal direction increased, and new, weak peaks due to twinning ${ }^{[15,16]}$ were observed (inserts in Figures 4(a)-(c)). The influence of twinning on texture evolution was nil at large strains (Figures 4(b) and (c)), and, due to the predominance of slip, the texture had started to become slightly split toward TD basal texture with a high intensity.

Before deformation, there were no twins in the CP Ti sample with an initial grain size of $15 \mu \mathrm{m}$. In the interval of 5 to 20-pct reduction, a considerable increase of twins was observed. However, new twins appeared not to form after 30-pct reduction (Figure 5(a)). Rather, microstructure evolution after this level of deformation was mainly associated with the formation of subgrains. At 60-pct reduction, many small, almost equiaxed grains/subgrains were observed (Figure 5(b)).
In addition, the microstructure contained relatively large grains consisting of the remnants of twins and poorly developed substructure. After 93-pet reduction, a mixed microstructure consisting of small, nearly equiaxed (sub)grains and large elongated grains with well-developed substructure were noted (Figure 5(c)). The average (sub)grain size was $0.2 \mu \mathrm{m}$. Texture evolution for $15-\mu \mathrm{m}$ starting condition was associated with some weakening of the basal-normal component and the appearance of new peaks due to twinning (Figures 5(a) and (b)). By 60 pet reduction, the influence of twinning on texture had saturated, and the texture started to become similar to that observed in the initial condition (Figure 5(c)). However, the texture components after heavy cold rolling were sharper and had higher intensity. More detailed description of microstructure and texture evolution during cold rolling of $\mathrm{CP} \mathrm{Ti}$ with an initial grain size of $15 \mu \mathrm{m}$ can be found elsewhere. ${ }^{[17]}$

Microstructure evolution at the beginning of deformation of the CP Ti sample with an initial grain size of $30 \mu \mathrm{m}$ was also dominated by twinning. With increasing reduction, twins which had been formed earlier became noticeably wider, and small secondary twins were formed within some of them (Figure 6(a)). However, the process of twinning occurred heterogeneously. In some grains, twins were frequently clustered into groups, while there were areas (comprising individual grains or groups of grains) which exhibited no twinning. In those grains for which twinning was extensive, deformation-induced boundaries and new small (sub)grains were observed at earlier stages of deformation (Figure 6(b)). At the same time, untwinned grains contained only LABs even after large levels of strain (Figure 6(c)). Overall, the microstructure of CP Ti with the initial grain size of 30 $\mu \mathrm{m}$ was refined to an average (sub)grain size of $0.6 \mu \mathrm{m}$ following the 93-pct thickness reduction.

The changes in texture during deformation of $\mathrm{CP} \mathrm{Ti}$ sample with an initial grain size of $30 \mu \mathrm{m}$ were also associated with twinning (both primary and secondary) which led to the appearance of multiple weak peaks ${ }^{[15,16]}$ (inserts in Figures 6(a) and (b)). However, it should be noted that the area scanned during EBSD for the results in Figures 6(a) and (b) may have been too small for the determination of statistically valid textures. Despite this possibllity, the observed texture changes did follow the broad trends for texture evolution during cold rolling of 
$\mathrm{CP}$ Ti. At large strains (when twinning is not active and slip becomes the main deformation mode ${ }^{[8]}$, the pole figure did evolve to one comprising the basal-normal texture typical of heavily rolled titanium ${ }^{[15,16]}$ (Figure 6(c)).

\section{B. Features of Twinning}

According to the EBSD analysis, in the beginning of deformation (first 15-20 pct strain), the most active twinning system in the CP Ti samples with initial grain sizes of 7,15 , and $30 \mu \mathrm{m}$ was the $\{10 \overline{1} \overline{2}\}\langle 10 \overline{1} \overline{1}\rangle$ (tensile), while the $\{11 \overline{2} 2\}\langle 11 \overline{2} \overline{3}\rangle$ (compressive) system was more than 1.5 times less active (Figures 7(a)-(c)). During further deformation, the contribution of these two twinning systems gave a nearly equal contribution. Other twining systems were rare and thus contributed a small amount to the accommodation of the imposed deformation. Although there were some differences between the fractions of twin boundaries in the $\mathrm{CP} \mathrm{Ti}$ samples with different grain sizes (Figures 7(a)-(c)), it appeared that the preferably activated twinning systems did not depend on the initial grain size. This observation likely resulted from the similar starting textures and identical mode of deformation.

Neither optical microscopy nor EBSD analysis showed any sign of twinning during deformation of CP Ti samples with an initial grain size of $1 \mu \mathrm{m}$. However, more detailed TEM investigation revealed the presence of discrete, thin (20-40 nm wide) twins after 10 pet reduction (Figure 8(a)). Indexed diffraction patterns from the twin/matrix (Figure 8(a)) indicated reflections of $(10 \overline{1} 1),(11 \overline{2} 1)$, and $(01 \overline{1} 0)$ planes for the twin (indices in italics in Figure 8(b)) while the reflections for the matrix were $(\overline{2} 021)$ and (0002). The twin/matrix misorientation angle was thus found to be $\sim 84 \mathrm{deg}$ about $\langle 11 \overline{2} 0\rangle$, which is intrinsic for the $\{10 \overline{1} 2\}\langle 10 \overline{1} \overline{1}\rangle$ system. The number of twins appeared to increase with strain (Figure 8(c)). Despite the limited volume observable via TEM, it did appear that there was little increase in the fraction of twinned grains with increasing reduction, thus implying that new twins largely developed within the same grains. Furthermore, it is worth noting that twinning in this condition may be associated with the larger $(\sim 2.5 \mu \mathrm{m})$ grains in the relatively broad grain size distribution (Figure 1).

For the CP Ti samples with an initial grain size of $7 \mu \mathrm{m}$, the number of twins typically did not exceed 1 or 2 per grain. Twins formed mainly parallel to each other; secondary twins were rarely observed (Figure 9(a)).

For the CP Ti samples with an average grain size of 15 or $30 \mu \mathrm{m}$, the traces of the twins within a given grain were often not parallel, thus indicating the merging of more than one deformation twin of the same twin family as the deformation increased (Figures 9(b) and (c)). Larger starting grain size thus has facilitated the thickening of twins and the accommodation of deformation by both slip and further twinning (e.g., secondary twinning). The microstructure was therefore refined more extensively by secondary twinning and twin/twin intersections. In fact, secondary twinning was indeed observed for the two largest initial grain sizes; examples are shown in Figures $9(\mathrm{~b})$ and (c) with black triangles. The number of secondary twins increased with strain. By contrast, for smaller starting grain sizes, growing twins would have met a barrier (e.g., a grain boundary) that would have hindered their growth or prevented merger with other twin(s). Therefore, secondary twins were less prevalent in these cases because the primary twins were unable to accumulate enough (additional) plastic strain to nucleate secondary twins. In this regard, Salem et al. ${ }^{[18,19]}$ have found that high-purity titanium requires a strain of 0.05 for twin nucleation (onset of Stage B in their terminology). From such reasoning, it may also be concluded that material with a very large initial grain size can produce very wide primary twins which in turn would promote the formation of wide secondary, and possibly even some tertiary, deformation twins.

The as-formed twins for samples with initial grain sizes of 7, 15 and $30 \mu \mathrm{m}$ had mainly lenticular shapes of various widths. The width of both primary and secondary twins increased with strain; some became very wide, occupying the greater part of a grain, especially for the coarser-grain conditions. Specifically, quantitative analysis revealed a relationship between the initial grain size and the width of twins developed during deformation (Figure 10(a)); on average, samples with the initial grain sizes of $1,7,15$ and $30 \mu \mathrm{m}$ developed twins with the approximate (average) widths of $0.3,1.5$, 2.3 , and $3 \mu \mathrm{m}$, respectively, after a 10 -pct reduction.

The fraction of twinned grains after 10-pet reduction as a function of the initial grain size was also quantified by optical microscopy and SEM (for initial grain sizes $d=7-30 \mu \mathrm{m}$ ), or TEM (for $d=1 \mu \mathrm{m}$ ) (Figure 10(b)). These results clearly showed that the most extensive increase in the fraction of twinned grains occurred for initial grain sizes in the interval of $1-15 \mu \mathrm{m}$. A further increase in the initial grain size resulted in a limited increase in the fraction of twinned grains. This behavior can be explained by the fact that almost 80 pct of the grains for the $15-\mu \mathrm{m}$ material exhibited twinning. Some of those twins could have become nearly as large as the original grain size but would have had a softer crystallographic orientation. ${ }^{[18,19]}$ As alluded to above, secondary twinning would therefore become more active in the material with a larger starting grain size. On the other hand, for CP Ti with grain size $d \leq 1 \mu \mathrm{m}$, the data revealed that twinning was either very sluggish, thus not having a large effect on microstructure formation and mechanical behavior, or absent altogether due to grain boundaries acting as barriers to twin formation. It is also of import to note that the fraction of twinned grains in the specimen with an average grain size of $1 \mu \mathrm{m}$ (Figure 10(b)) was quantitatively similar to the fraction of "large" grains in the structure (i.e., with $d>2 \mu \mathrm{m}$, Figure 1). This finding thus supports the above conclusion that limited twinning in the $1-\mu \mathrm{m}$ material was likely the result of microstructure inhomogeneity.

\section{Kinetics of Microstructure Evolution}

The degree and rate of microstructure refinement during rolling of $\mathrm{CP}$ Ti samples with various initial grain sizes $d$ were further highlighted by quantitative EBSD 

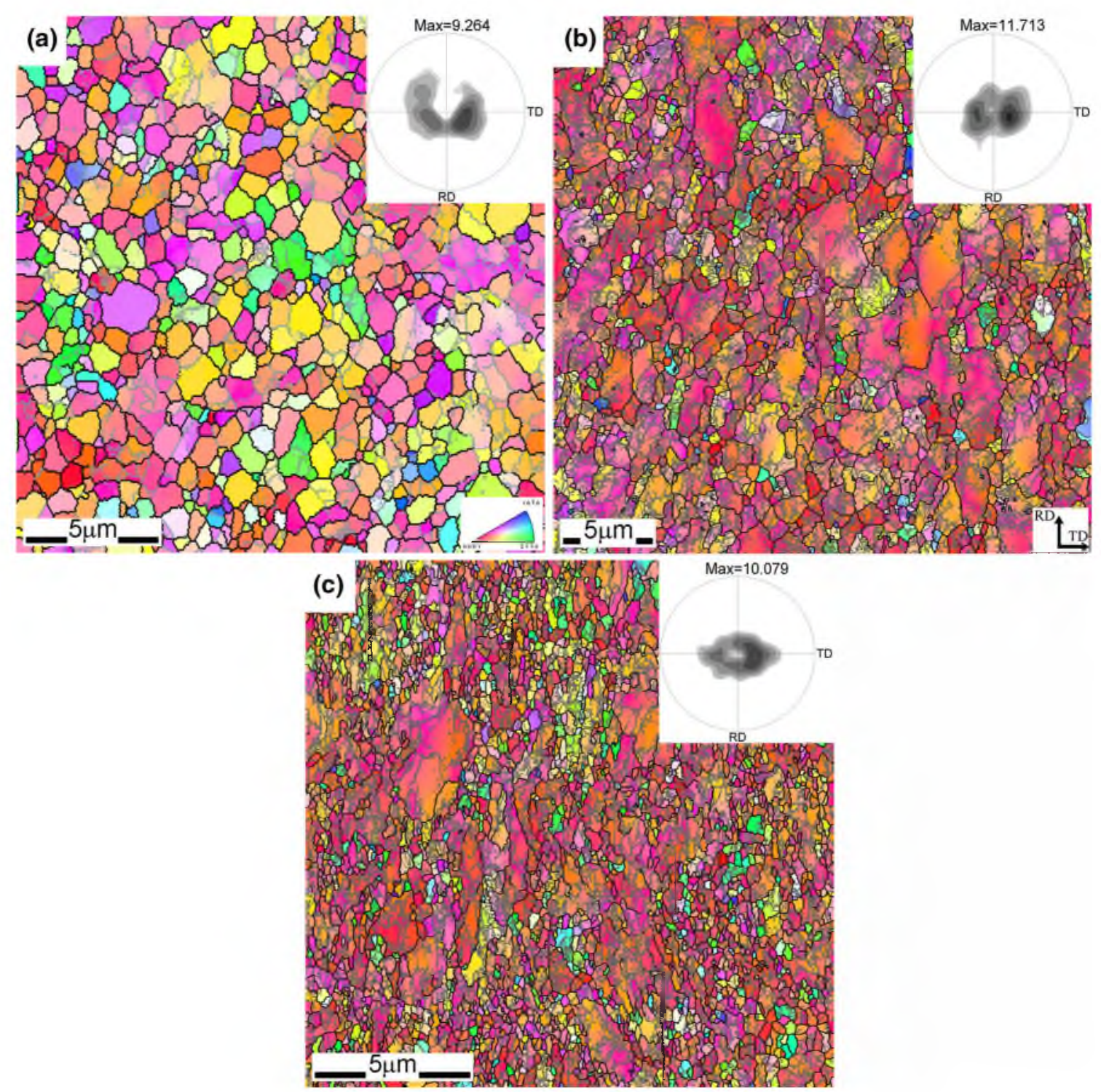

Fig. 3-Normal-direction EBSD (inverse-pole-figure) nnaps taken froin the rolling plane of CP Ti with an initial grain size of $1 \mu \mathrm{m}$ after thickness reductions (in pct) of $(a) 0,(b) 40$, and (c) 93. The RD is vertical in all cases.

measurements of the HABs and LABs (Figure 11). For CP Ti with $d=1 \mu \mathrm{m}$, two stages in the development of HABs were observed (Figure 11(a)): an initial stage (0 to 60 pet reduction) during which there was essentially no change in the density of HABs followed by a period of marked increase (reduction $>60 \mathrm{pct}$ ). By contrast, the density of LABs for this material increased monotonically with strain (Figure 11(b)) and exhibited values noticeably above those for all of the other samples with coarser initial grain sizes. These trends indicated that microstructure evolution for $\mathrm{CP} \mathrm{Ti}$ with the smallest initial grain size was dominated by slip activity rather than twinning, in agreement with the results in Reference 8 , and was likely due to subgrain development and the formation of deformation-induced HABs during the first and second stages, respectively.

For $\mathrm{CP}$ Ti with initial grain sizes $d=7,15$, and $30 \mu \mathrm{m}$, the evolution of $\mathrm{HAB}$ density as a function of reduction was described by a trilinear behavior in each case (Figure 11(a)). Although qualitatively very similar, the curves differed from each other with regard to the length of the stages, the positions of the inflection points, and, last, the rate of increase in the HABs at large reductions. For small reductions $(<10,20$, or 30 pct for $d=7,15$ or $30 \mu \mathrm{m}$, respectively), the noticeable increase in HABs density was obviously associated with twinning. The corresponding increase in $\mathrm{LAB}$ density for this interval of deformation was very slow because of twinning. During the second stage, the $\mathrm{HAB}$ density changed very little. In view of the rapid increase in the density of LABs during this stage (Figure 11(b)), this finding implied a saturation of twinning and the development of substructure as was shown previously for CP Ti with an initial grain size of $15 \mu \mathrm{m}^{[17,20]}$ and for high-purity $\mathrm{Ti}^{[18,19]}$ For the third stage, both the HAB and LAB densities increased markedly implying the formation of deformation-induced grain boundaries during large strains. 

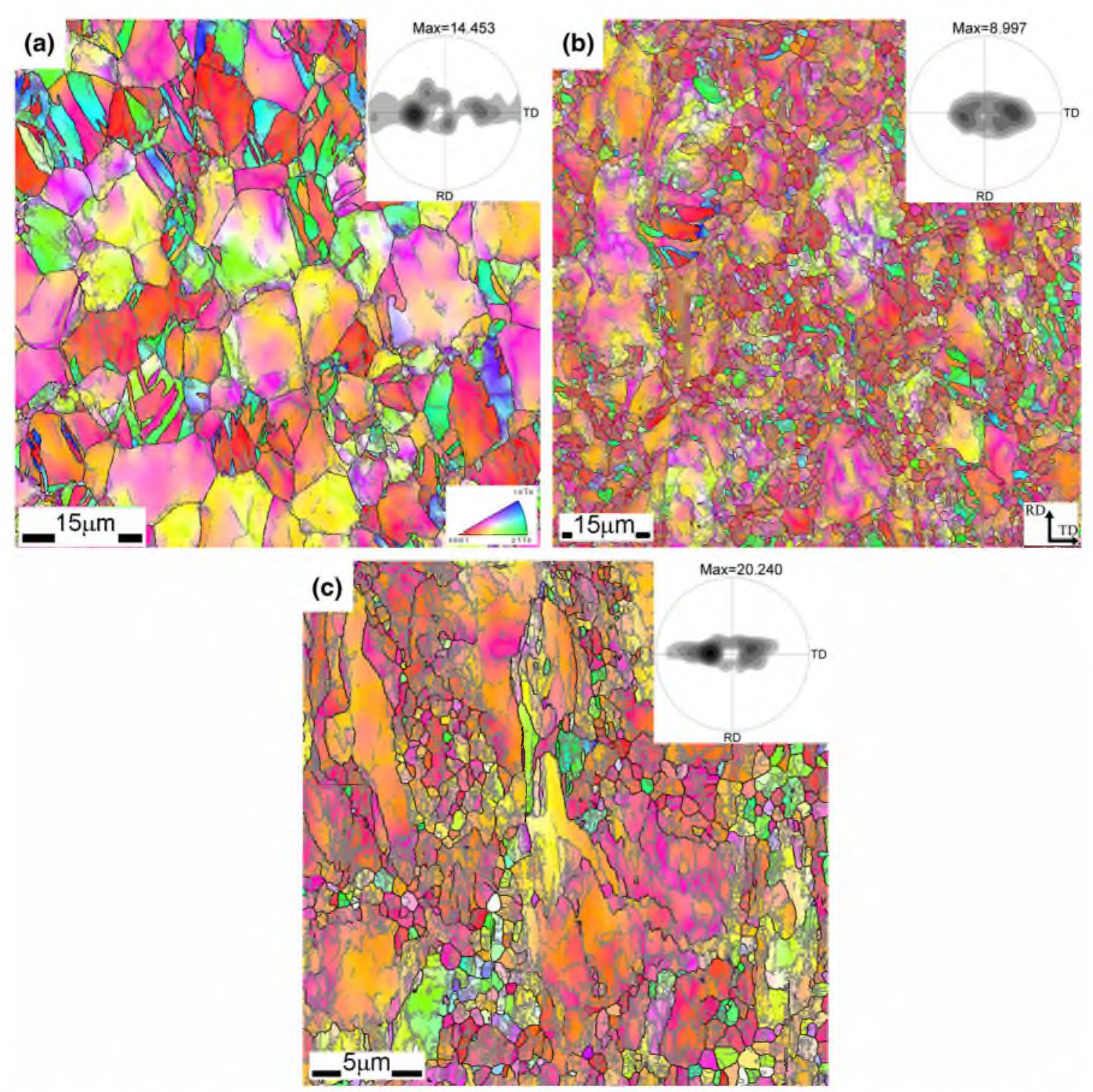

Fig. 4-Normal-direction EBSD (inverse-pole-figure) maps taken from the rolling plane of CP Ti with an initial grain size of $7 \mu \mathrm{m}$ after thickness reductions (in pet) of $(a) 30(b) 60$, and (c) 93 . The RD is vertical in all cases. Note the higher magnification of the image in (c).

Not surprisingly, the observed stages for the evolution of $\mathrm{HABs} / \mathrm{LABs}$ correlated well with the kinetics of grain refinement (Figure 12(a)). During the first stage, the microstructure in all of the twinned conditions (i.e., with initial grain sizes of 7,15 or $30 \mu \mathrm{m}$ ) became considerably refined due to twinning. For the second stage, during which slip dominated relative to twinning, refinement became much less pronounced. It then intensified again during the third stage. For $\mathrm{CP}$ Ti with an initial grain size of $1 \mu \mathrm{m}$, noticeable grain refinement was observed after 40-60 reduction in accordance with the increase in HAB density (Figure 11(a)).

The results in Figure 11 also have a direct correlation with prior observations of the mechanical behavior (plastic flow response) of unalloyed Ti. In particular, the three stages of $\mathrm{HAB}$ evolution via deformation twinning mirrored the three stages of strain hardening found for
CP Ti and high-purity Ti. $\left.{ }^{[18} 20\right]$ The first stage of HAB formation (Figure 11(a)) can be deduced to be a reflection of Stage $\mathrm{A}$ and $\mathrm{B}$ with its increasing hardening rate due to deformation twinning. ${ }^{[18]}$ The second stage is analogous to the third stage (Stage $\mathrm{C}$ in Reference 18) of decreasing strain hardening rate, which is associated with the saturation of deformation twinning. Although the third stage in Figure 11(a) is characterized by increases in both $\mathrm{HAB}$ and $\mathrm{LAB}$ after the saturation of deformation twinning, it is still part of the decreasing strain hardening rate, Stage $C^{[18]}$ This observation is crucial for the formulation of constitutive models describing material behavior in view of the fact that an increase in HABs and LABs (and grain refinement) does not necessarily indicate an increase in the strain hardening rate because of the possibly mitigating influence of texture softening. ${ }^{[18,19]}$ 

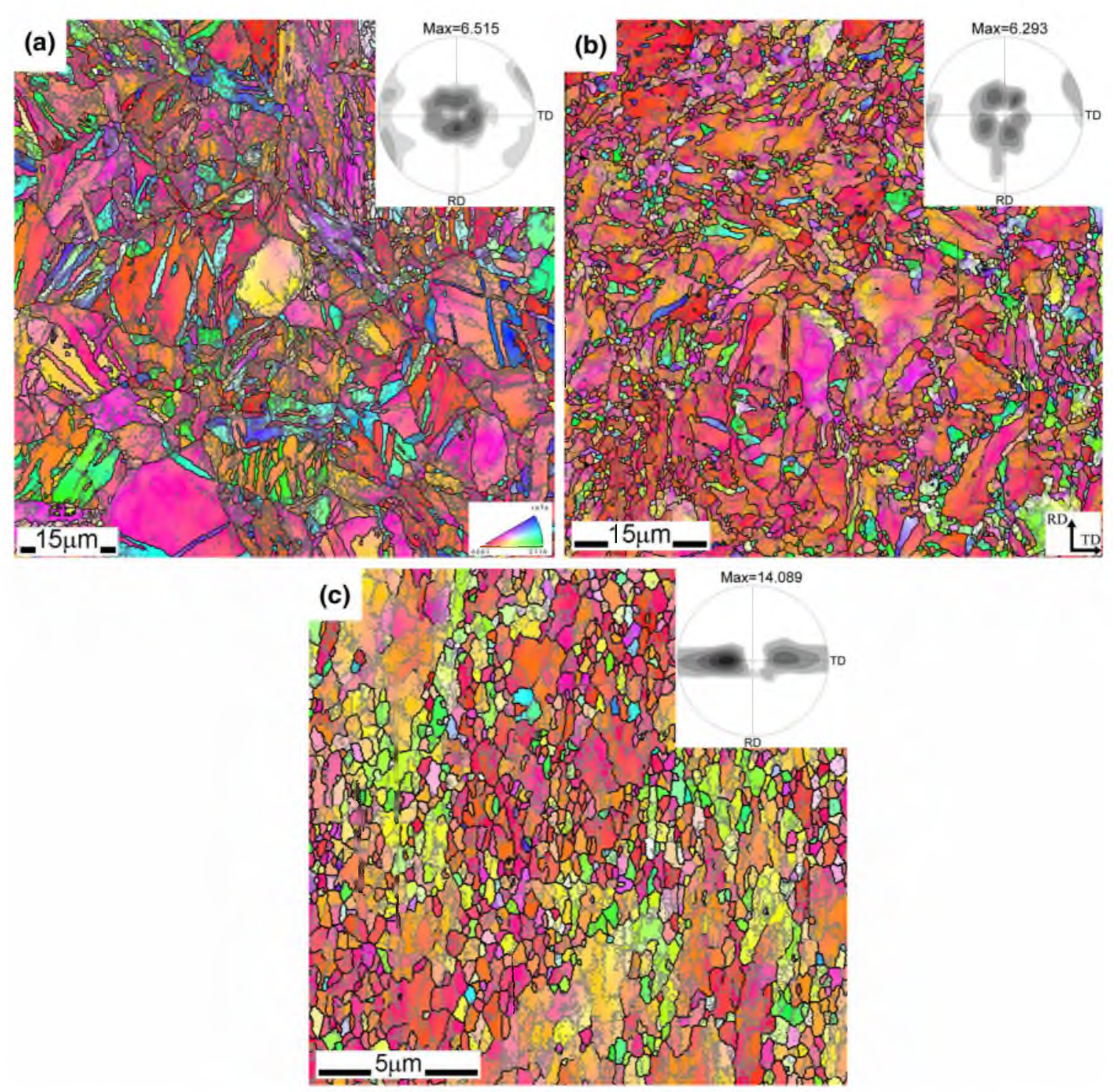

Fig. 5-Normal-direction EBSD (mverse-pole-figure) maps taken from the rolling plane of CP Ti with an mitial gram size of $15 \mu \mathrm{m}$ after thickness reductions (pct) of (a) 30, (b) 60, and (c) 93. The RD is vertical in all cases. Note the different magnifications of the images.

Estimates of the relative decrease with strain of the grain size $\left(\left(d-d_{\mathrm{c}}\right) / d\right.$, where $d$ and $d_{\mathrm{c}}$ denote the initial and current grain sizes, respectively) indicated more efficient microstructure refinement for the twinned conditions (Figure 12(b)). Moreover, more extensive twinning (for CP Ti with $d=15$ and $30 \mu \mathrm{m}$ ) promoted microstructure refinement in comparison with the kinetics for CP Ti with $d=7 \mu \mathrm{m}$.

Several other findings associated with the stages in the evolution of the $\mathrm{HAB} / \mathrm{LAB}$ density and the kinetics of microstructure refinement (Figures 11 and 12) were noteworthy. First, the onset of the third stage corresponded to $\sim 40$-pct reduction for all initial grain sizes that underwent a large amount of twinning during rolling. That is to say, a noticeable increase in the density of high-angle deformation-induced boundaries required approximately the same level of strain. On the other hand, for the fine-grain condition $(d=1 \mu \mathrm{m})$ which did not deform by twinning, the level of deformation at which extensive deformation-induced HABs formed was considerably higher, i.e., 60-pct reduction. Second, the grain size at the end of the first stage (2-3 $\mu \mathrm{m}$, Figure 12) was very similar for each of the highly twinned conditions. Last, the absolute value of the HAB density developed in $\mathrm{CP}$ Ti during deformation depended on the initial grain size. The highest density of both HABs and LABS was observed for $1-\mu \mathrm{m}$ samples over the entire range of deformation. For the highly twinned conditions, the density of both HAB and $\mathrm{LAB}$ boundaries behaved similar to each other. For CP Ti with $d=15 \mu \mathrm{m}$, however, the HAB density at 40-pet reduction was slightly higher than that for $\mathrm{CP}$ Ti with $d=7$ or $30 \mu \mathrm{m}$.

\section{DISCUSSION}

The present results showed a strong effect of initial grain size in $\mathrm{CP} \mathrm{Ti}$ on microstructure evolution during large deformation. The major difference in the kinetics 

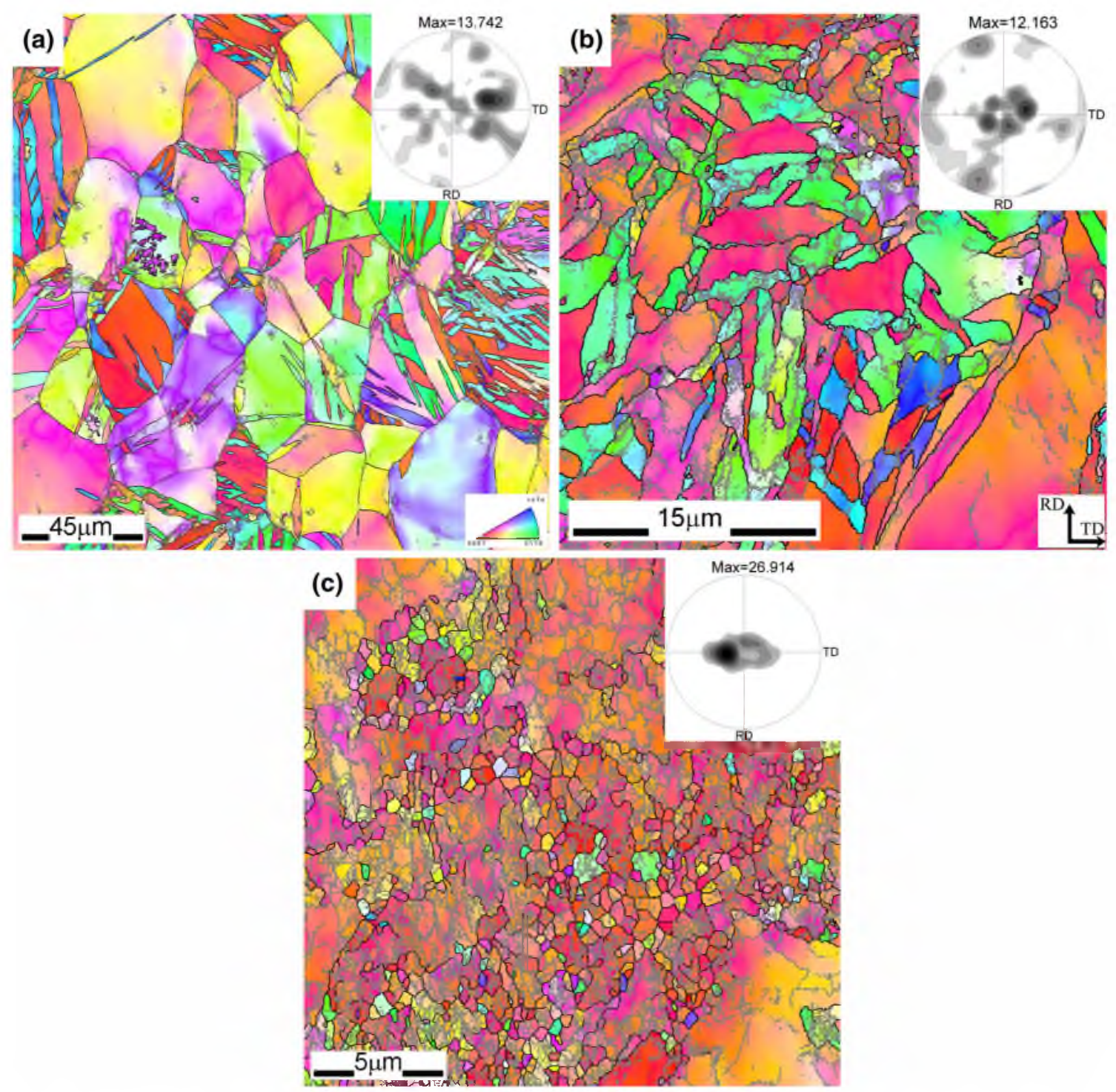

Fig. 6-Normal-direction EBSD (mverse-pole-figure) maps taken from the rolling plane of CP Ti with an initial grain size of $30 \mu \mathrm{m}$ after thickness reductions (m pct) of $(a) 30,(b) 60$, and (c) 93. The RD is vertical in all cases. Note the different magnifications of the images.

of microstructure refinement was observed for conditions comprising an initial grain size of $1 \mu \mathrm{m}$ vs $7-30 \mu \mathrm{m}$, obviously because of differences in the activity of twinning.

The dependence of twinning on grain size is a complex phenomenon. A number of earlier investigations for various metallic systems $\left.{ }^{[4,21} 23\right]$ have shown a strong dependence of flow stress on grain size for the deformation interval controlled by twinning or slip. These well-established results have suggested that twinning in smaller-grain size conditions requires higher stresses than slip. In addition, a decrease in grain size increases the homogeneity of the strain distribution due to the large fraction of neighboring grains in which the stress level needed to activate twinning is not reached. Despite considerable past efforts to explain the suppression of twinning with a decrease in grain size, a comprehensive physical explanation of this phenomenon has yet to be proposed and validated.
One of the most straightforward prior approaches to explain the twinning phenomenon involves a comparison of the grain size $d$ and the length of pile-ups $l$ responsible for the onset of twinning or a critical twin embryo size $r$. If a Frank-Read dislocation source is located at the center of a grain, the condition for twinning can be given in the form $2 l<d$. Various numerical evaluations have given the number of dislocations in the pile-up as $N \approx 30,{ }^{[24]}$ while the length of pile-ups was found to be $34 \mathrm{~nm}$ (for $\mathrm{Cu}$ ), ${ }^{[4]}$ which is well below the grain size for which twinning is inactive. Similarly, the critical size of a twin embryo $r$ corresponding to a minimum in the free energy for metals with different types of crystal structures (FCC, BCC, and HCP) has been estimated to be $\sim 10$ to $70 \mathrm{~nm} .{ }^{[4]}$ The latter calculation was based on the classical inclusion theory of Eshelby. ${ }^{[25]}$ This theory can also be used to describe the geometric parameters for growing twins corresponding to a minimum in the free energy for an 

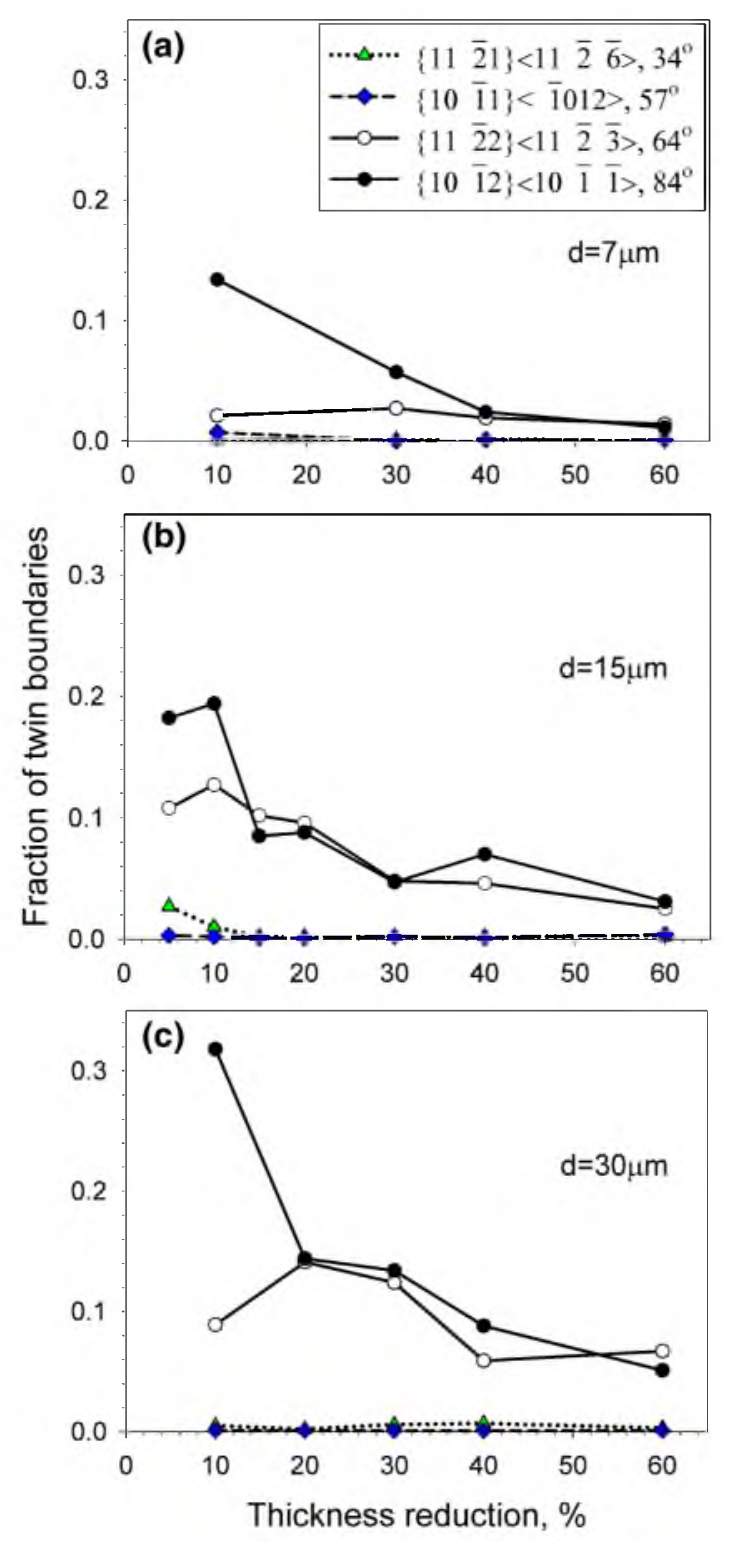

Fig. 7-The fraction of twin boundaries of various twin systems in the whole amount of high-angle boundaries as a function of stram during cold rolling of titanium with the mitial graim sizes of $(a)$ $7 \mu \mathrm{m}:$ (b) $15 \mu \mathrm{m}$ : and (c) $30 \mu \mathrm{m}$. ellipsoidal elastic "inhomogeneity." The twin aspect ratio $q(q=t / l$, in which $t$ is the twin thickness and $l$ is the twin length) for a given slip system was found to be $q \propto \tau$, where $\tau$ is the applied shear stress. Such a relation was originally derived for FCC metals by Venables ${ }^{[26]}$ and then repeated for various other types of crystal structures by Lebensohn and Tome ${ }^{[27]}$ and Meyers. ${ }^{[4]} \mathrm{A}$ very similar relation was also derived by Friedel on the basis of a dislocation loop model. ${ }^{[28]}$ Combining $l \approx d^{[29]}$ and $\tau \propto 1 / \sqrt{ } d$ (the Hall-Petch equation), this relation can be used to explain the increase in twin thickness in a coarse-grained material (Figure 10(a)). However, the physical reasons for the predominance of slip over twinning in fine-grain metals remain unclear. In addition, it should be noted that the twin aspect ratio found for $d=1 \mu \mathrm{m}$ in the present work does not follow the common trend predicted by the relation $q \propto \tau$.

Although there are different reasons for deformation twinning in cubic and hexagonal lattices (low stacking fault energy or low symmetry, respectively), the mechanism of twin nucleation and growth in all cases has been suggested to be associated with the cooperative motion of an array of partial dislocations. ${ }^{[23,30,31]}$ In other words, twinning can be considered to be a result of the formation of a partial wedge disclination dipole (Figure 13(a)) and its motion (Figure 13(b)). This approach was first proposed by Romanov and Kolesnikova. ${ }^{[30]}$ Later, a theoretical model describing the formation of deformation twins due to the cooperative motion of partial dislocations emitted by the grain boundary was developed by Gutkin et al. ${ }^{[31]}$

According to Reference 30, the formation of the so-called misorientation bands (regions of lattice misorientated with respect to the surrounding volume; these regions have one dimension smaller than the other two and include twins, kink bands, deformation bands, etc.) are associated with rotational deformation. In contrast to shear (or translational) strain which is associated with dislocation slip, rotational deformation is carried out by the movement of disclinations. The formation of disclinations or disclination dipoles at grain boundaries or triple junctions results in the generation of high elastic stresses $^{[30]}$ which in turn lead to the heterogeneous generation of partial (dissociated) dislocations at grain
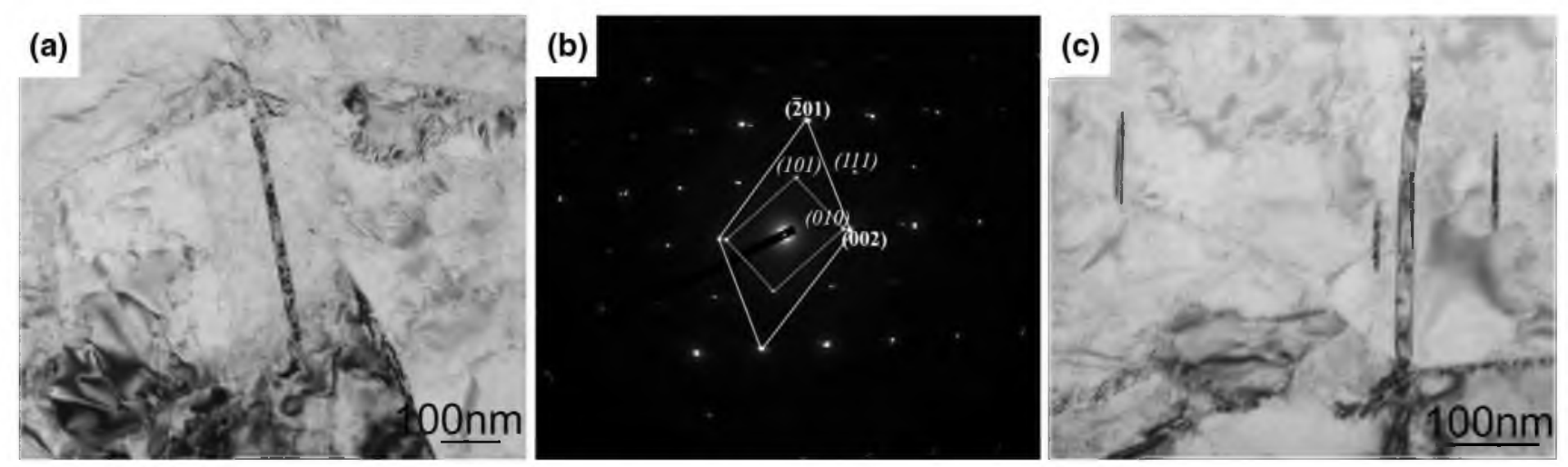

Fig. 8-TEM micrographs for CP Ti with an initial grain size of $1 \mu \mathrm{m}$ after thickness reduction (in pct) of (a) 10 and (c) 30 . The SAED pattern corresponding to (a) is shown in (b). 

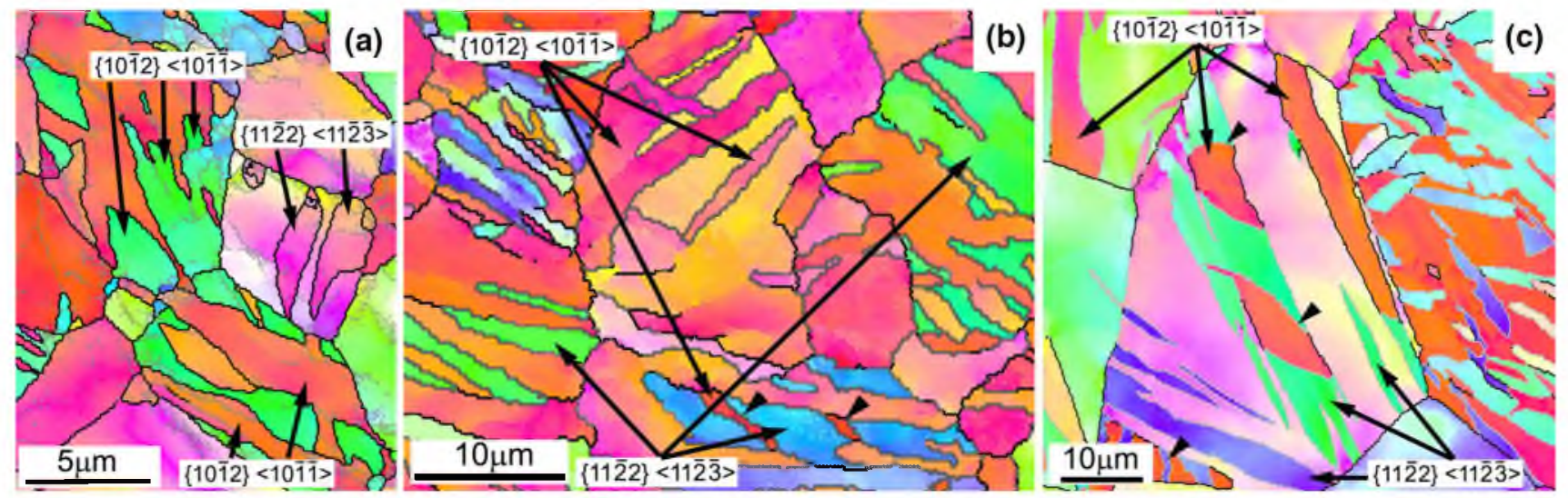

Fig. 9-EBSD results showing the development of twins after 30-pct thickness reduction of CP Ti samples with the initial grain sizes ( $\mu \mathrm{m}$ ) of (a) $7,(b) 15$, and (c) 30 .

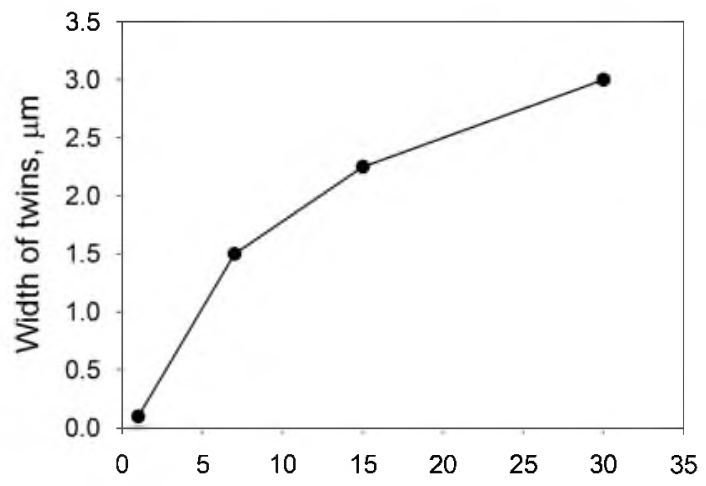

(a)

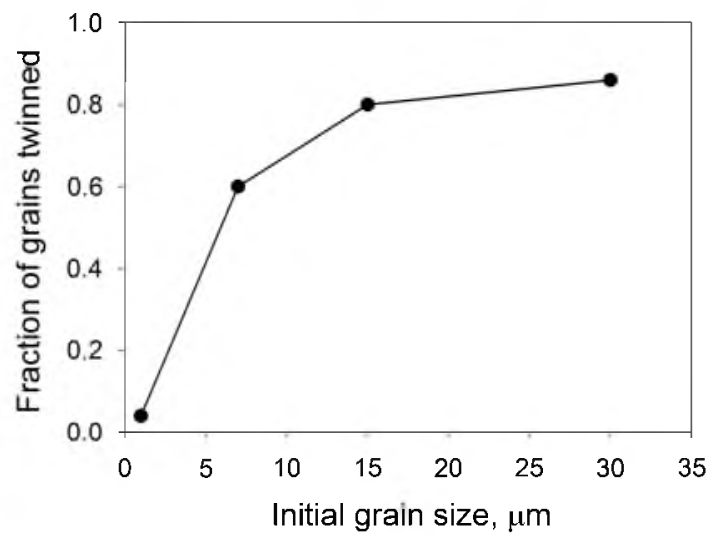

(b)

Fig. 10-The 1neasured dependence on initial grain size of $(a)$ the width of twins and $(b)$ the fraction of twinned grains in CP Ti after cold rolling to a 10-pct thickness reduction. Optical microscopy and EBSD data were used for the larger $(d=7-30 \mu \mathrm{m})$ grain sizes; the fraction of twinned grains in case of the sinall $(d=1 \mu \mathrm{m})$ initial grain size was evaluated by TEM.

boundaries. $\left.{ }^{[31}{ }^{36}\right]$ The cooperative glide of such dislocations with overlapping stacking faults can effectively produce deformation twins. ${ }^{[36,37]}$

A disclination dipole can be described as a finite succession of edge dislocations with very small Burgers vectors which are introduced into a crystalline lattice. ${ }^{[30]}$

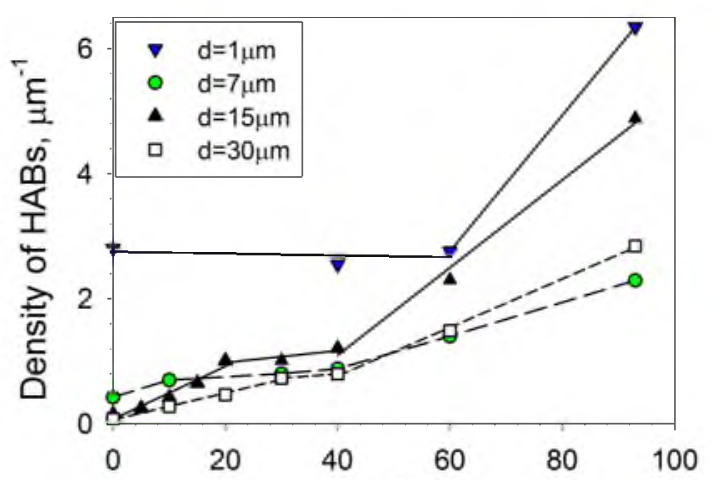

(a)

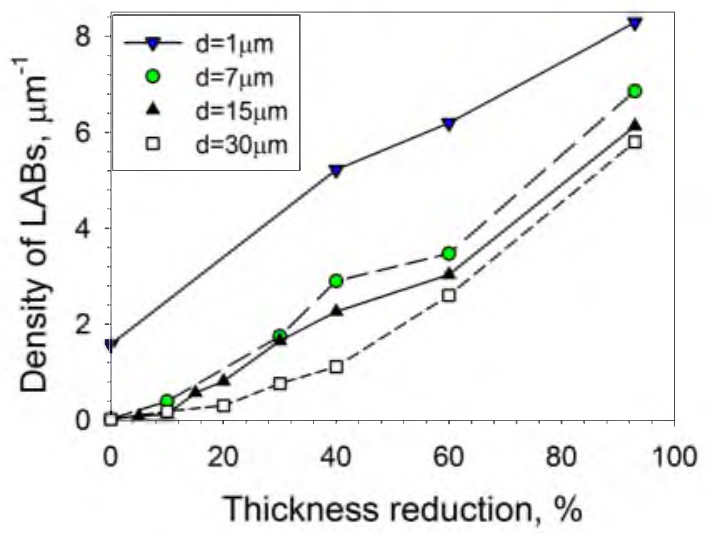

(b)

Fig. 11-Evolution of density of HABs $(a)$ and LABs $(b)$ during cold rolling of $\mathrm{CP}$ Ti with different grain sizes; EBSD data were used in all cases.

Moving through the grain, the disclination dipole leaves a twin behind. The driving force of such motion is the release of elastic distortion when the disclination dipole reaches the opposite side of the grain. The twins which are formed are assumed to have the highest Schmid factor. The energy of the disclination dipole $E_{\mathrm{d}}$ depends on the shielding radius $R$ (Figure 13(a)), the length of the disclination dipole $L$, and the power of disclination $\omega$ as ${ }^{[30]}$ 


$$
E_{\mathrm{d}}=\frac{D \omega^{2} L^{2}}{2}\left(\ln \frac{R}{L}+\frac{1}{2}\right)
$$

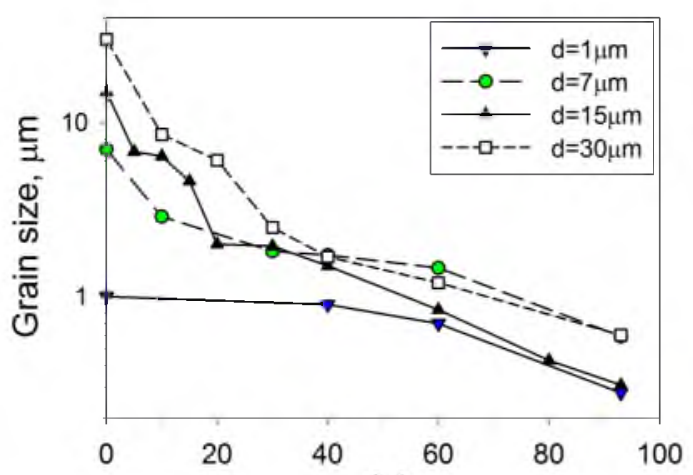

(a)

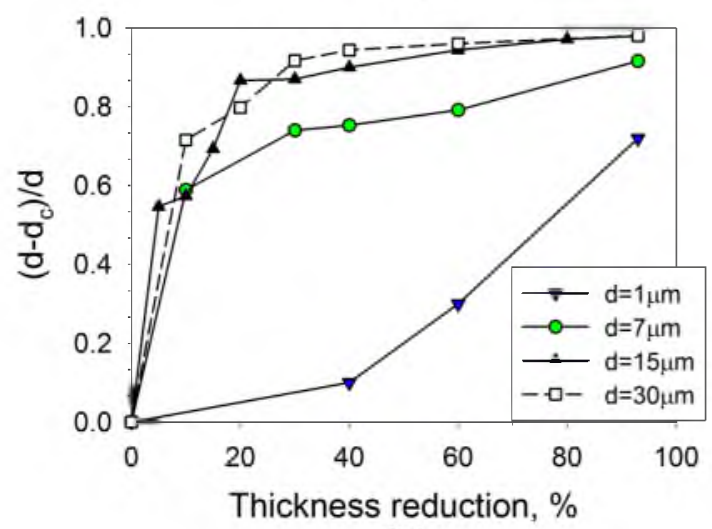

(b)

Fig. 12-The effect of reduction and initial grain size on microstructure refinement in terms of $(a)$ grain size or $(b)\left(d-d_{c}\right) / d$, in which $d$ and $d_{\mathrm{c}}$ denote the initial and current grain size, respectively. Grain size was ineasured by optical inicroscopy and EBSD after lower strains and by EBSD and TEM after strains $\varepsilon \geq 60$ pct.
Here, $D=G /[2 \pi(1-v)]$, in which $G$ is the shear modulus, and $v$ is Poisson's ratio. The energy of the disclination dipole influences its mobility and thus the ease of twin formation. Furthermore, the shielding radius and the length of the disclination dipole correlate

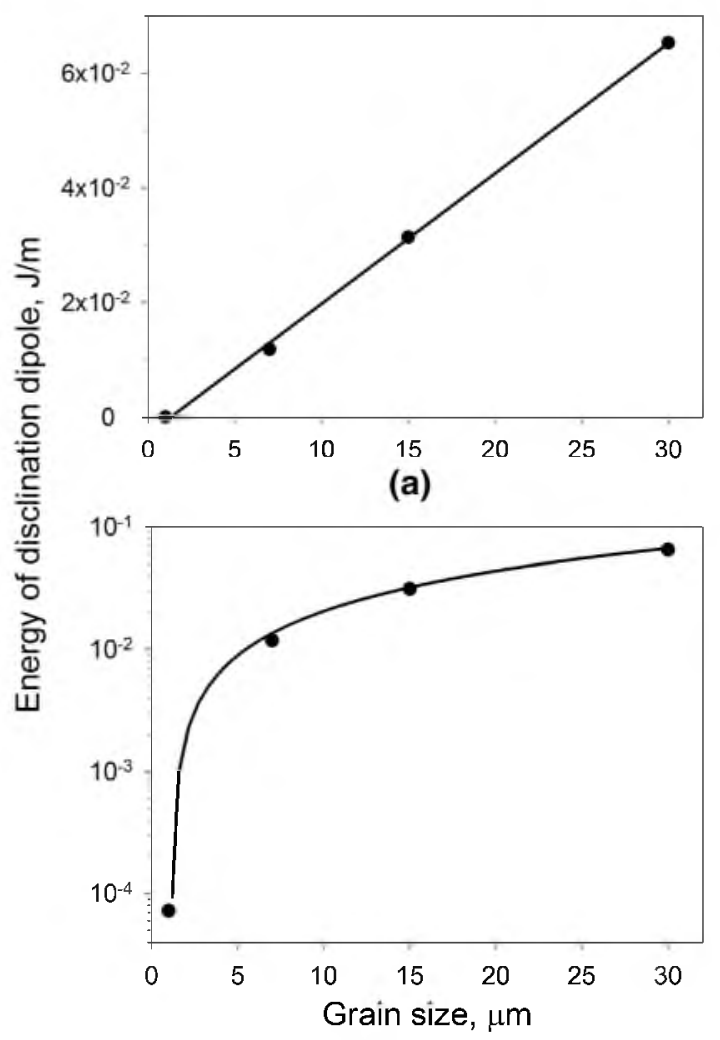

(b)

Fig. 14-Energy of a disclination dipole as a function of grain size in $(a)$ linear and $(b)$ semilogarithmic coordinates.

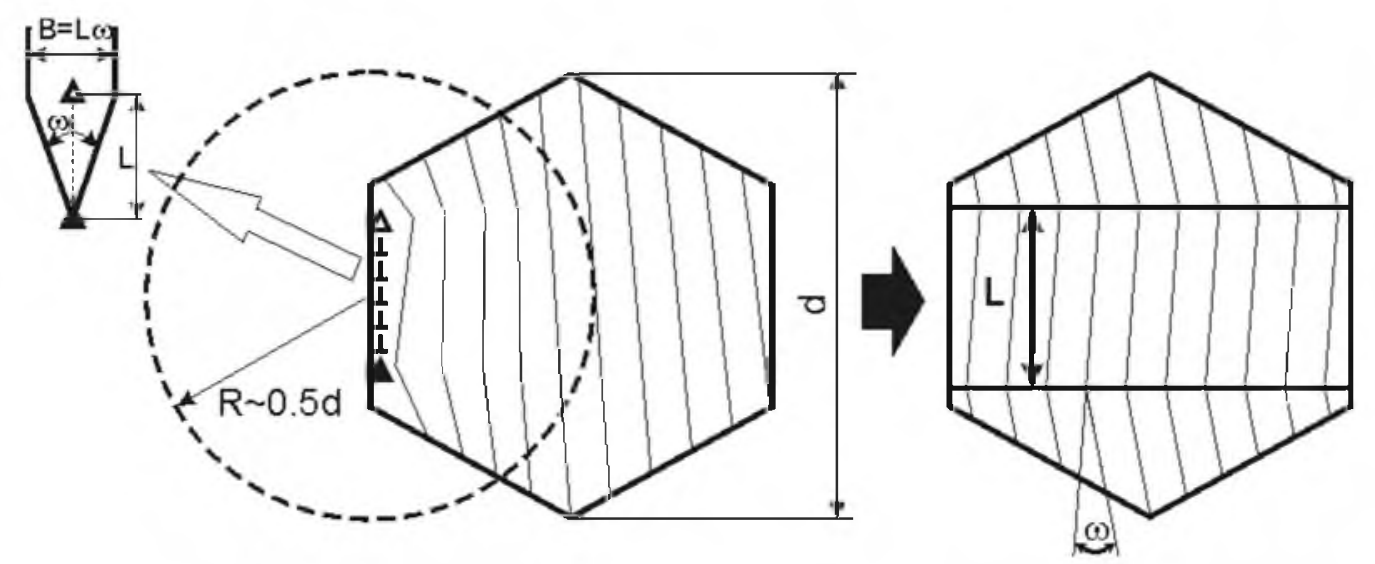

(a)

(b)

Fig. 13-Schenatic illustration of $(a)$ the elastic crystal lattice distortion associated with a disclination dipole near a grain boundary and (b) the result of the notion of the disclination dipole through a grain in the formation of a twin. Some of the paraineters describing the disclination dipole are shown in the top left corner of (a). 
to the grain size $d$. Therefore, a decrease in the grain size decreases the energy of the disclination dipole.

The disclination dipole energy as a function of grain size can be calculated assuming $R=d / 2, L=t$ $(t=$ twin width, Figure $10(\mathrm{a}))$, and $\omega=0.5 .^{[31]}$ The relationship thus obtained (Figure 14(a)) can be approximated as a straight line that almost reaches zero energy at a grain size of $1 \mu \mathrm{m}$. Replotting this relation in semilogarithmic coordinates (Figure 14(b)) reveals a pronounced decrease in the energy (by more than two orders of magnitude) over the grain size interval from 7 to $1 \mu \mathrm{m}$. These results suggest that the energy of disclination dipoles for grain sizes below $\sim 5-7 \mu \mathrm{m}$ becomes too low to initiate twinning. By contrast, it should be noted that the energy of a disclination dipole in $\mathrm{Ti}$ with a grain size of $1 \mu \mathrm{m}$ (Figure 14(b)) is approximately ten orders of magnitude higher than the energy for twin nucleation derived using the inclusion theory, ${ }^{[27]}$ i.e.,

$$
\Delta G_{\mathrm{T}}=\frac{2}{3} \pi a_{\mathrm{cr}}^{2} \gamma \Gamma_{\mathrm{T}},
$$

in which $a_{\mathrm{cr}}$ is the critical size of a twin embryo, $\gamma$ is the twin aspect ratio, and $\Gamma_{\mathrm{T}}$ is the surface energy.

The approach based on the disclination model gives good agreement of predictions and experimental data (e.g., Figures 14(b) vs 10(b)) and thus deserves further careful study.

\section{CONCLUSIONS}

Microstructure evolution in commercial-purity titanium with various initial grain sizes $(1,7,15$, and $30 \mu \mathrm{m})$ subjected to plane-strain multipass rolling to a true thickness strain of 2.66 at $293 \mathrm{~K}\left(20^{\circ} \mathrm{C}\right)$ was investigated. The following conclusions are drawn from this work:

1. The extent of deformation twinning depends strongly on grain size. The twin volume fraction was almost negligible in material with an average grain size of $1 \mu \mathrm{m}$ and attained a maximum (close to $100 \mathrm{pct}$ ) for grain sizes above $15 \mu \mathrm{m}$.

2. The different extents of twinning lead to different kinetics of microstructure refinement. For initial conditions consisting of grain sizes of 7,15 and $30 \mu \mathrm{m}$, the density of HABs can be described by a three-stage curve. These stages are associated with twinning, the development of subgrain boundaries, and the formation of high-angle deformation-induced boundaries. For $\mathrm{CP}$ Ti with an initial grain size of $1 \mu \mathrm{m}$, two stages associated with the development of subgrains and the formation of high-angle deformation-induced boundaries are observed.

3. Due to twinning-induced microstructure refinement, rolling to a true thickness strain of 2.66 results in the formation of an ultrafine-grain microstructure with a grain/subgrain size of 200-300 $\mathrm{nm}$ in CP Ti with an initial grain size of $15 \mu \mathrm{m}$, a value similar to that for material with an initial grain size of $1 \mu \mathrm{m}$. The final microstructure of titanium with an initial grain size of 7 or $30 \mu \mathrm{m}$ consists of $\sim 600-\mathrm{nm}$ grains and subgrains.

4. The disclination model provides a plausible explanation for the effect of grain size on deformation twinning in titanium. In the present work, reasonable quantitative agreement between model predictions and observations for the transition grain size below which twinning is unlikely was obtained.

\section{ACKNOWLEDGMENTS}

The authors gratefully acknowledge the financial support from the Ministry of Education and Science, Russia (Belgorod State University, Project No. $11.1816 .2014 / \mathrm{K})$. The authors are grateful to the personnel of the Joint Research Centre, Belgorod State University, for their assistance with the experimental analysis.

\section{REFERENCES}

1. F.J. Humphreys and M. Hatherly: Recrystallization and Related Annealing Phenomena, 2nd ed., Elsevier Science Ltd., Oxford, United Kingdom, 2004, pp. 451-66.

2. A. Belyakov, K. Tsuzaki, H. Miura, and T. Sakai: Acta Mater.. 2003 , vol. 51 , pp. 847-61.

3. M. El Wahabi, L. Gavard, F. Montheillet, J.M. Cabrera, and J.M. Prado: Acta Mater., 2005, vol. 53, pp. 4605-12.

4. M.A. Meyers, O. Vöhringer, and V.A. Lubarda: Acta Mater.. 2001, vol. 49 , pp. $4025-39$.

5. E. El-Danaf, S.R. Kalidindi, and R.D. Doherty: Metall Mater. Trans. A, 1999, vol. 30A, pp. 1223-33.

6. N. Stanford, U. Carlson, and M.R. Barnett: Metall. Mater. Trans. $A, 2008$, vol. 39 A, pp. 93444

7. M.R. Barnett, Z. Keshavarz, A.G. Beer, and D. Atwell: Acta Mater., 2004, vol. 52, pp. 5093-5103.

8. S.V. Zherebtsov, G.S. Dyakonov, A.A. Salem, V.I. Sokolenko, G.A. Salishchev, and S.L. Semiatin: Acta Mater., 2013, vol. 61, pp. 1167-78.

9. Q. Yu, Z.-W. Shan, J. Li, X. Huang, L. Xiao, J. Sun, and E. Ma: Nature, 2010, vol. 463, pp. 335-38.

10. G.A. Salishchev and S.Yu. Mironov: Russian Phys. J., 2001, vol. 44 , pp. 596-601.

11. S. Zherebtsov, E. Kudryavtsev, S. Kostjuchenko, S. Malysheva. and G. Salishchev: Mater. Sci. Eng. A, 2012, vol. 536, pp. 190-96.

12. M. Kong, R.N. Bhattacharya, C. James, and A. Basu: Geol. Soc. Am. Bull., 2005, vol. 117, pp. 244-49.

13. D.G. Brandon: Acta Metall., 1966, vol. 14, pp. 1479-84.

14. L. Capolungo, P.E. Marshall, R.J. McCabe, I.J. Beyerlem, and C.N. Tome: Acta Mater., 2009, vol. 57, pp. 6047-56.

15. N. Bozzolo, N. Dewobroto, H.R. Wenk, and F. Wagner: J. Mater Sci., 2007, vol. 42, pp. 2405-16.

16. Y.B. Chun, S.H. Yu, S.L. Semiatim, and S.K. Hwang: Mater. Sci. Eng. A, 2005, vol. 398, pp. 209-19.

17. S.V. Zherebtsov, G.S. Dyakonov, A.A. Salem, S.P. Malysheva, G.A. Salishchev, and S.L. Semiatin: Mater. Sci. Eng. A, 2011. vol. 528 , pp. $3474-79$.

18. A.A. Salem, S.R. Kalidindi, and R.D. Doherty: Acta Mater., 2003, vol. 51, pp. 4225-37.

19. A.A. Salem, S.R. Kalidimdi, R.D. Doherty, and S.L. Semiatm: Metall. Mater. Trans. A, 2006, vol. 37A, pp. 259-68.

20. A.A. Salem, S.R. Kalidindi, R.D. Doherty, M.G. Glavicic and S L. Semiatin: in Ti-2003 Science and Technology, G. Luetjering, J. Albrecht, eds., Wiley, Weinheim, 2004.

21. V.F. Moiseev and V.I. Trefilov: Phys. Stat. Sol., 1966, vol. 18, pp. $881-95$. 
22. R.W. Armstrong and P.J. Worthington: in Metallurgical Effects at High Strain Rates, R.W. Rohde, B.M. Butcher, J.R. Holland, C.H. Karnes, eds., Plenum Press, New York, 1973, pp. 401-14.

23. J.W. Christian and S. Mahajan: Progr. Mater. Sci., 1995, vol. 39 pp. $1-157$.

24. S. Mahajan: Scripta Mater., 2013, vol. 68, pp. 95-99.

25. J.D. Eshelby: Proc. R. Soc. Lond. A, 1957, vol. 241, pp. 376-96.

26. J.A. Venables: J. Phys. Chem. Solids, 1964, vol. 25, pp. 693-700

27. R.A. Lebensohn and C.N. Tome: Phil. Mag. A, 1993, vol. 67. pp. 187-206.

28. J. Friedel: Dislocations, Pergamon Press, Oxford, 1964, pp. 208-20

29. A. Ghader and M.R. Barnett: Acta Mater., 2011, vol. 59, pp. 7824-39

30. A.E. Romanov and A.L. Kolesnikova: Progr. Mater. Sci., 2009 vol. 54 , pp. $740-69$.
31. M. Yu. Gutkm, I.A. Ovid'ko and N.V. Skiba: Phys. Rev. B, 2006. vol. 74, pp. 172107(1-4).

32. G.B. Olson and M. Cohen: Metall. Trans. A, 1976, vol. 7. pp. 1897-1904.

33. Y.T. Zhu, X.Z. Liao, S.G. Srinivasan and E.J. Lavernia: J. Appl. Phys., 2005, vol. 98, pp. 034319(1-8).

34. M.Yu. Gutkm and I.A. Ovid'ko: Plastic Deformation in Nanocrystalline Materials, Springer, Berlin, 2004

35. T. Shimokawa, A. Nakatani and H. Kitagawa: Phys. Rev. B, 2005. vol. 71, pp. \#224110(1-8).

36. I.A. Ovid'ko and N.V. Skiba: Scripta Mater., 2014, vol. 71, pp. 33-36.

37. J.P. Hirth and J. Lothe: Theory of Dislocations, Wiley, New York, 1982, pp. 811-34. 